\title{
Configuraciones del cuidado de larga duración en España y Francia: dos modelos contrapuestos ${ }^{1}$
}

\section{Paloma Moré}

Departamento de Sociología III-Estructura Social, Facultad de Ciencias Políticas y Sociología, Universidad Complutense de Madrid

<mmore@ucm.es>

Artikulu honetan konparatzen da epe luzeko pertsona adinduen zainketen inguruko antolaketa soziala Espainia eta Frantzian, eta betekizun horretarako hartu dira Madril eta Parisen buruturiko bi kasu-azterketa. Batetik, bi azterketa horien konparazioak ahalbidetzen du zainketen jarduera “desnaturalizatzea", eta modu horretan eskaintzen da gertuko diren bi herrialderen antolaketarako modu oso desberdinak aztertzea. Bestetik, modu kritiko batean aztertzen dira izaera profesionala lortzeko herrialde bietan hautatu diren ildoak, eta modu horretan aztertzen dira kasu bakoitzean etxeko jarduera eta gizarte-baliabideen artean egituratzen diren bi ereduak. Doktoretzarako ikerkuntza bateko testuinguruko izaera kualitatiboa oinarri hartuz burutu da artikulu hau.

\section{GAKO-HITZAK:}

Generoa, migrazioak, profesionalizatzea, etxebizitzarako zerbitzuak, etxez etxeko laguntza, egoitzak
Este artículo analiza de manera comparada la organización social de los cuidados de larga duración para personas mayores en España y Francia a través de dos estudios de caso realizados en las ciudades de Madrid y París. La comparación permite, por un lado, “desnaturalizar" el trabajo de cuidados, ofreciendo dos ejemplos de formas de organización muy diferentes en países vecinos; por otro lado, analizar de manera crítica los procesos de profesionalización que se han emprendido en cada uno de los dos países, observando cómo se articulan con modelos ligados a la domesticidad y a la ayuda social que perduran en cada uno de los dos casos. El artículo se ha elaborado a partir del material de tipo cualitativo, obtenido en el contexto de una investigación doctoral.

\section{PALABRAS CLAVE:}

Género, migraciones, profesionalización, servicio doméstico, ayuda a domicilio, residencias.

\footnotetext{
${ }^{1}$ Esta investigación ha sido financiada por una beca predoctoral FPI-UCM (2011-2015), dirigida por Juan José Castillo Alonso, y realizada en la Facultad de Ciencias Políticas y Sociología de la Universidad Complutense de Madrid, dentro del programa de doctorado en Migraciones Internacionales e Integración Social del Instituto Universitario de Investigación Ortega y Gasset. El estudio de caso en París se realizó durante una estancia de investigación (febrero-octubre 2013) en el equipo GTM-CRESPPA del CNRS, bajo la tutela de Helena Hirata. El estudio de caso de Madrid ha sido realizado dentro del marco de dos proyectos de investigación: WOMINTRA (ref. 06/10), dirigido por M. C. La Barbera y financiado por el Instituto de la Mujer y el FSE; RETOSCRISIS (ref. CSO 2013-43666-R), dirigido por Santiago Castillo y Pablo López Calle, y financiado por el Ministerio de Ciencia e Innovación, Programa Estatal de Proyectos de Investigación I+D+i.
} 


\section{Introducción}

El objetivo de este artículo es analizar, desde una perspectiva comparada y critica, los procesos de profesionalización de los cuidados de larga duración (CLD) en dos países europeos: España y Francia. La comparación internacional se plantea como un instrumento de análisis privilegiado para desnaturalizar los cuidados, al comprender que las sociedades europeas desarrollan distintos modelos sociales como solución a la necesidad creciente de tales cuidados en contextos de envejecimiento de la población (Lyon y Glucksmann, 2008; MartínezBuján, 2011; Shutes y Walsh, 2012). En este sentido, España y Francia suponen dos modelos muy diferentes de organización de las respuestas a sus necesidades de cuidados de la población mayor, pues mientras que España es un ejemplo de cuidados "domésticos", Francia ha desarrollado una política de profesionalización de esos cuidados. Sin embargo, como se pretende ilustrar en el artículo, estos modelos no sólo responden a la consideración del envejecimiento de la población, sino a otras preocupaciones y fenómenos sociales, como las relaciones de género, las migraciones internacionales, la segmentación del mercado de trabajo y las políticas de empleo.

El artículo se estructura en cinco apartados. En el primero, se expone el abordaje metodológico que ha dado lugar a los resultados de investigación que se presentan a continuación. En el segundo, se introducen algunos de los elementos teóricos que constituyen el marco del estudio. En los apartados tres y cuatro, se analizan las configuraciones de los cuidados de larga duración en Madrid y en París, y los efectos específicos que dichos marcos tienen sobre el desarrollo de las trayectorias laborales de quienes prestan esos servicios. En el último apartado, se exponen las conclusiones finales del artículo.

\section{Metodología}

El texto expone los resultados de una investigación doctoral realizada entre 2011 y 2015 en la que se compara el cuidado de personas mayores en Madrid y París. La metodología utilizada combina varias técnicas de investigación con un enfoque cualitativo.

El proceso de investigación comenzó por el estudio del cuidado de personas mayores en la ciudad de Madrid, donde el empleo de hogar y, en concreto, el que se realiza en régimen "interno" tiene mucha importancia, pero se articula con un sistema de cuidados más formalizado. Estas dos formas de cuidados tienden a complementarse, y es frecuente que las personas que se dedican al cuidado de ancianos tengan o hayan tenido experiencia como empleadas de hogar. Por ello, la estrategia metodológica se ha centrado en analizar el importante lugar que ocupa el servicio doméstico en Madrid. Así, se realizaron 23 entrevistas en profundidad con trabajadoras que habían "circulado" por las distintas formas de empleo de cuidados de larga duración (servicio doméstico interno y externo, ayuda a domicilio y residencias). Esto se complementó con cinco entrevistas grupales en las que las trabajadoras pusieron en común sus experiencias y se privilegió el contraste entre las visiones más "profesionales" de aquellas que tenían experiencia en cuidados formales y las visiones más “domésticas” de aquellas que, sobre todo, habían trabajado como empleadas de hogar en función de cuidadora. Además, se realizó observación participante en locales de búsqueda de empleo, agencias privadas e instituciones religiosas para ver la inserción laboral y la importancia de la búsqueda constante de empleo; en una asociación de trabajadoras de cuidados, para estudiar el proceso de profesionalización; así como en una residencia de ancianos, para analizar las prácticas más institucionalizadas y profesionales. Fue imposible, debido a la repetida negativa de empresas privadas e instituciones locales, realizar observación en los servicios de ayuda a domicilio del Ayuntamiento de Madrid.

Con el propósito de seleccionar comparar el modelo “doméstico" madrileño dentro de Europa, se realizó un estudio de caso en la ciudad de París. Esta ciudad ofrecía un ejemplo idóneo para contrastar la realidad de Madrid, pues, por un lado, se trata de una gran ciudad donde los cuidados son un sector feminizado y "etnicizado" en el que trabaja mucha población de origen inmigrante; por otro lado, la organización de los cuidados presenta una configuración que, a grandes rasgos, puede llamarse "profesional" o en proceso de profesionalización. Se constató que las trayectorias de las trabajadoras estaban más segmentadas, en función de las distintas formas de trabajo, y eran menos cíclicas que las de Madrid, por tanto, se realizaron un total de 42 entrevistas para poder abarcar los distintos subsectores: 10 en empleo de hogar ( 7 de las cuales habían sido internas); 17 en ayuda a domicilio; y 15 que trabajaban en una residencia. Además, se realizó observación participante de cada una de estas tres formas de trabajo: en primer lugar, en una parroquia que gestiona empleos informales de cuidados en el hogar; en segundo, en una asociación de servicios de ayuda a domicilio que acompaña a las trabajadoras en sus jornadas laborales; y por último, en una residencia de personas mayores, donde se realizó un seguimiento de las/los trabajadoras/es en los distintos turnos del funcionamiento del centro.

Esta información se completó con 18 entrevistas a distintas figuras sociales que, por su trabajo, eran claves para entender la configuración de los cuidados en cada uno de los dos casos: personal técnico de los servicios sociales, personal directivo de las empresas y asociaciones de ayuda a domicilio, personal directivo y técnico de residencias de mayores, religiosas que gestionan los empleos domésticos informales y una directora de agencia de servicio doméstico.

A través de esta metodología, se ha podido establecer una caracterización concreta, basada en situaciones 


\begin{tabular}{|c|c|c|c|}
\hline & Entrevistas con trabajadoras/es & Entrevistas con informantes clave & Observación participante \\
\hline Madrid & $\begin{array}{l}\text { - } 23 \text { trabajadoras/es que habían } \\
\text { pasado por las distintas formas de } \\
\text { empleo. } \\
\text { - } 5 \text { entrevistas grupales: } 3 \text { a } \\
\text { demandantes de empleo en cuidados; } \\
1 \text { a empleadas de hogar; } 1 \text { a auxiliares } \\
\text { de ayuda a domicilio que antes } \\
\text { habían sido empleadas de hogar. }\end{array}$ & $\begin{array}{l}\text { - } 12 \text { entrevistas con distintos actores: } \\
\text { personal técnico de administraciones } \\
\text { públicas (Ayuntamiento de Madrid } \\
\text { y Comunidad de Madrid); personal } \\
\text { con cargos de responsabilidad en } \\
\text { residencias, empresas de ayuda } \\
\text { a domicilio, agencias de empleo } \\
\text { doméstico, congregaciones religiosas } \\
\text { y asociaciones de inmigrantes. }\end{array}$ & $\begin{array}{l}\text { - Asociación de mujeres inmigrantes y } \\
\text { trabajadoras de cuidados. } \\
\text { - Bolsas de empleo privadas y religiosas } \\
\text { de servicio doméstico. } \\
\text { - Seguimiento de las rutinas de trabajo } \\
\text { en distintos turnos en una residencia } \\
\text { municipal. } \\
\text { - Visitas a otras residencias. }\end{array}$ \\
\hline París & $\begin{array}{l}42 \text { trabajadoras/es en tres } \\
\text { subsectores: } 10 \text { que trabajaban en } \\
\text { empleo de hogar; } 17 \text { trabajadoras/es } \\
\text { de los servicios de ayuda a domicilio } \\
\text { de una asociación; } 15 \text { trabajadoras/ } \\
\text { es de una residencia (auxiliares y } \\
\text { personal de limpieza). }\end{array}$ & $\begin{array}{l}\text { - } 6 \text { entrevistas con distintos actores: } \\
\text { personal técnico de administraciones } \\
\text { públicas (CNSA); personal con cargos } \\
\text { de responsabilidad en residencias, } \\
\text { empresas de ayuda a domicilio y } \\
\text { congregaciones religiosas. }\end{array}$ & $\begin{array}{l}\text { - Institución religiosa que gestiona } \\
\text { empleos en hogares. } \\
\text { - Seguimiento a auxiliares en sus } \\
\text { intervenciones a domicilio. } \\
\text { - Seguimiento de las rutinas de trabajo, } \\
\text { en distintos turnos, en una residencia } \\
\text { privada. }\end{array}$ \\
\hline
\end{tabular}

Fuente: Elaboración propia.

concretas de trabajo, de las distintas formas de organización del trabajo cuidados de larga duración a personas mayores en cada una de las dos ciudades.

\section{Perspectivas para el estudio del trabajo de cuidados y las migraciones internacionales}

Según la definición de Fisher y Tronto, cuidar es una actividad genérica que comprende todo aquello que hacemos para mantener, perpetuar y reparar nuestro "mundo", para que podamos vivir en él lo mejor posible. Este mundo comprende nuestros cuerpos, a nosotros mismos y a nuestro entorno, elementos todos ellos que se articulan en una red compleja de sostenimiento de la vida (1990: 40)². En efecto, el trabajo de cuidados tiene la especificidad de entrelazar de manera profunda tres dimensiones que son fundamentales para su desempeño: material, emocional y moral (Martín-Palomo, 2008: 28). El trabajo de cuidados se asocia a menudo a lo inmaterial -los afectos, el amor, las emociones-, pero igualmente importante es su vertiente material, de trabajo efectivo $y$, a veces, técnico. Sin embargo, el cuidado tiene también una dimensión material incuestionable, pues si bien se trata de una actividad genérica (que puede tomar diversas formas), está orientada a "hacer algo" (un trabajo) para dar una respuesta, efectiva y concreta, a una necesidad (Molinier, 2006: 301). Estas tres dimensiones - ética, material y emocionalson diferentes, pero están completamente unidas y difícilmente pueden aislarse en la experiencia de la gente, y mucho menos en la de quienes día a día se ven inmersos en situaciones que reclaman su disponibilidad y actividad física, su implicación emocional y su criterio y responsabilidad ética.

Al analizar el sector de los cuidados, la feminización salta a la vista. Una constante histórica, y que

2 "Care is all we do to maintain, continue, and repair our 'world' so that we can live in it as well as possible". persiste en nuestros días, es que la responsabilidad de los cuidados recae sobre las mujeres como si se tratara de tareas "naturalmente" asignadas al sexo femenino (Guimarães et al., 2011). Los cuidados son parte esencial de la construcción social del género femenino y, por tanto, tienen asignado un valor social secundario en relación con otras actividades consideradas esenciales para el funcionamiento de la sociedad. Así, si bien los cuidados son imprescindibles para la reproducción social, el sistema económico y político en el que vivimos está lejos de situarlos en el centro de sus preocupaciones (Carrasco, 2013: 51; Pérez-Orozco, 2014: 47). De esta manera, los cuidados, como parte del trabajo doméstico o de reproducción, son todavía hoy asimilados a un asunto privado, y no se reconocen sus implicaciones y repercusiones sociales, políticas y económicas.

Las diversas actividades comprendidas bajo el concepto genérico de trabajo de cuidados las realizan las mujeres, principalmente pero no sólo en el marco familiar, de manera gratuita, bajo una obligatoriedad moral y una norma de disponibilidad total, dándose por supuestas, y reclamando poca atención y reconocimiento. Por ello, cuando estas actividades se mercantilizan, se reproducen esas características y se convierten en empleos poco lucrativos, informales, con horarios imposibles que reclaman disponibilidad total y, muchas veces, sin contratos laborales. Se trata de empleos que portan una "precariedad en femenino" (Dussuet, 2005) y que son ocupados principalmente por mujeres de clase social baja. En este proceso de mercantilización, las desigualdades de género asociadas a la división sexual del trabajo (Kergoat, 2000) se articulan, además, con otras formas de desigualdad, como la clase social y la división internacional del trabajo. Por ello, los empleos destinados al cuidado de personas mayores, tanto en Madrid como en París, son mayoritariamente ocupados por mujeres migrantes, racializadas o de origen obrero. Debido a que habitualmente se trata de empleos poco valorados, las personas que en ellos trabajan tienen poco poder de negociación y escasas oportunidades de promoción. 
En el artículo, se analiza cómo la organización social de los cuidados de larga duración en cada una de estas dos ciudades se configura gracias a la interacción de los regímenes migratorios, y cómo esta interacción moldea trayectorias de las personas que alimentan el sector. En este sentido, se han analizado las posibilidades de carrera en el ámbito de los cuidados que existen en cada uno de los dos casos estudiados. La noción de carrera se entiende como una interacción entre agencia y estructura en la que el género es un elemento fundamental, y no como proceso lineal o una sucesión consecutiva de empleos en línea ascendente (Evetts, 2000; Cuzzocrea y Lyon, 2011). Además, la carrera laboral se articula con las limitaciones y las oportunidades que ofrecen, a su vez, los procesos migratorios en los que muchas de las trabajadoras del sector están inmersas. De esta manera, el concepto incorpora también una dimensión de movilidad espacial, social y política dentro del ámbito de las migraciones internacionales. La carrera migratoria constituye un proceso dinámico, que no es unidireccional ni lineal, que se construye tanto objetiva como subjetivamente, y cuya evaluación de éxito o fracaso no es automática, sino que tiene una enorme complejidad" (Martiniello y Rea, 2014: 1084). Así, el género, la clase social y la etnicidad/estatus migratorio contribuyen a moldear las carreras de las trabajadoras (en su gran mayoría se trata de mujeres) dentro del ámbito de los cuidados de larga duración, pero están, a su vez, enmarcadas en la configuración social del cuidado vigente en cada ciudad.

\section{Configuración del cuidado en Madrid: una generación de empleadas "internas"}

\subsection{Los cuidados son "cosa de familia"}

En España, la organización social del cuidado depende todavía en gran medida del trabajo gratuito de las mujeres dentro de las familias, siendo el cuidado familiar la principal fuente de cuidados de larga duración para personas mayores, y la utilización de servicios públicos, una alternativa minoritaria. Una aproximación cuantitativa al fenómeno muestra que mientras que la ayuda familiar es la primera opción para un $85,3 \%$ de los mayores de 65 años que reciben asistencia personal, los servicios públicos sólo cubren el 5,9\% de los adultos mayores con dependencia, y como cuidadores principales, sólo en el 2,9\% de los casos (Martínez-Buján, 2011). De acuerdo con Martínez-Buján, la división sexual y generacional de los cuidados no desaparece, sino que se mantiene estable, y la única transformación que se aprecia es una tendencia a la mercantilización de los cuidados, pero sin dejar de ser una cuestión privada, que las familias deben resolver por sus propios medios.

De todas las posibilidades que existen, la preferente es el servicio doméstico. Según la Encuesta EDAD 2008, las cuidadoras domésticas son el 10,4\% de los asistentes principales a mayores, y el $14,5 \%$ si se tiene en cuenta a cuidadores de hogar secundarios (ibídem: 100-102). Según los datos de varias fuentes estadísticas correspondientes al periodo previo a la crisis, el recurso al empleo de hogar para el cuidado de mayores había aumentado, en detrimento de los servicios públicos. Así, contratar a una empleada de hogar cuidadora no es un signo de riqueza ni de ostentación, sino más bien una salida rápida, flexible y urgente que utilizan las familias de clase media para suplir la falta de servicios públicos y dar preferencia a un modelo doméstico.

Las instituciones públicas cuentan con esta realidad de que las familias, ante situaciones difíciles de resolver, van a recurrir al mercado privado para contratar a una persona "interna" que resuelva los cuidados de larga duración, retrasando al máximo posible la intervención de los servicios públicos. Así lo explicaba uno de los informantes clave del ámbito institucional, a quien se entrevistó en Madrid:

Efectivamente, la empleada de hogar, que en realidad es "la interna”, garantiza a la familia que esa persona mayor que vive sola está atendida entre semana, y el fin de semana, pues los hijos echan una..., la relevan para que pueda tener su descanso... Es el sector de lo que podemos llamar los cuidados informales, que cubre un amplio sector de la clase media para las personas que llamamos frágiles, las personas mayores de 80 años, que viven solas, pero que todavía no están, vamos, que no se les reconocería como dependientes o como dependientes de un grado importante, pero que no las puedes dejar solas en casa, porque pueden tener un accidente al cocinar, etc., y que, vamos, la solución intermedia, preferida por el propio mayor y por los hijos, pues es esta persona que pasa a convivir con ellos". (Dirección General del Mayor, Comunidad de Madrid, 2012)

El régimen de cuidados y el régimen migratorio se articulado en España de tal manera que han dando lugar a la expansión del servicio doméstico destinado a cuidados de larga duración para personas mayores. Según la Encuesta EDAD, el $71 \%$ de las empleadas domésticas cuidadoras de mayores de 64 años en España son extranjeras, proporción que asciende al $94 \%$ cuando trabajan como "internas". La feminización asciende al $98 \%$, y en cifras absolutas, se trata de 71.194 empleadas de hogar cuidadoras extranjeras en España y de 10.602 en la Comunidad de Madrid (Rodríguez et al., 2012: 168-171). El empleo de hogar destinado a cuidados de larga duración es parte de un fenómeno más amplio, que consiste en la mercantilización de los cuidados y del trabajo doméstico por la vía del empleo de hogar.

\subsection{Una generación de "internas"}

Durante las décadas de 1990 y 2000, la inmigración se convirtió en un "fenómeno social" en España (Cachón, 2009) y, al mismo tiempo, se duplicó el número de personas ocupadas en el empleo de hogar, un sector que perdía efectivos desde 
hacía una década y se creía en vías de extinción. Además, se produjo una revitalización del régimen de empleo de hogar “interno" (Martínez-Buján, 2014: 297) una modalidad de empleo que requiere que la trabajadora resida en el domicilio de sus empleadores y que se ha extendido particularmente en el caso del cuidado a personas mayores, para asegurar una atención personalizada 24 horas al día. Así, al contrario de lo que se esperaba en los años ochenta (vid. Sallé, 1985), este sector no sólo no desaparecía, sino que crecía en efectivos e importancia, y se convertía en la principal ocupación para las mujeres procedentes de países como Ecuador y Filipinas (más del 80\%) o República Dominicana y Perú (más del $70 \%$ ), según datos de la Tesorería de la Seguridad Social analizados por el Colectivo loé (2001: 108). Como señala Parella (2004: 159), el empleo de hogar se convirtió durante los años noventa en la principal vía de acceso al empleo de la fuerza de trabajo femenina inmigrante, al igual que sucedía anteriormente con las mujeres autóctonas que emigraban del campo a la ciudad (vid. Sallé, 1985; Colectivo loé, 1990; Sarasúa, 1994).

La composición en términos de nacionalidades y países de procedencia ha ido cambiando según la evolución de la política migratoria de visados, de la estabilización y regularización de la población inmigrante asentada en España, y por el establecimiento de nuevos flujos migratorios (Colectivo loé, 2001: 244-250), pero la pauta de la etnicización del sector se ha mantenido hasta la actualidad. Según los datos de la Encuesta Nacional de Inmigrantes (ENI), realizada en 2007 , el servicio doméstico - esta es la terminología que aparece en la encuesta- era la ocupación en la que más mujeres migrantes habían encontrado su primer empleo, independientemente de cuál fuera su origen social o procedencia. El análisis de los microdatos realizado por Vidal-Coso y Miret (2009: 14) refleja que el 42,2\% de todas las mujeres encuestadas habían entrado en el mercado laboral a través de este sector. Las mujeres procedentes de los países andinos estaban sobrerrepresentadas, y alcanzaban el $73 \%$ de las de origen boliviano, el $55 \%$ de las procedentes de Ecuador y Perú, y el $48 \%$ de quienes procedían de Colombia (Colectivo loé y Fernández, 2010: 110).

King y Zontini (2000) analizan los países de la Europa mediterránea en clave de la segmentación étnica y de género del mercado laboral, enfatizando, por tanto, los factores estructurales de la discriminación. Es necesario considerar que el hecho de que el empleo de hogar haya sido la puerta de entrada -y en muchos casos, la única posibilidad de mantenerse ocupadas-de muchas mujeres migrantes en España es el resultado especifico y concreto de su posición subordinada en la intersección de las estructuras de desigualdad en términos de género, clase, "raza" y estatus migratorio. Por un lado, en la sociedad española las mujeres, en general, y las nativas, en particular, soportan una posición estructuralmente desigual en el mercado de trabajo, derivada de la desigualdad de género en la sociedad y de la responsabilidad por el trabajo doméstico (Carrasco y Mayordomo, 1999; Torns, 1995); por otro lado, la segmentación étnica del mercado laboral es también una pauta estructural constante (Pajares, 2009; Colectivo loé y Fernández, 2010), reforzada por un "marco institucional discriminatorio" (Cachón, 2009) y por el fomento de la irregularidad a través de la política migratoria (Arango, 2005).

La desigualdad interseccional que enfrentan las mujeres migrantes en España ha tenido su máxima expresión en el Real Decreto 1424/1985³ , en vigor hasta que fue reemplazado por el Real Decreto 1620/2011. Esta legislación permitía mantener un sector flexible y desregulado. Por tanto, la ausencia de derechos civiles y laborales para las empleadas de hogar no suponía una irregularidad, sino que se ajustaba a la norma jurídicamente legitimada (Colectivo loé, 2001).

Tal y como señala mucha de la investigación sobre el empleo de hogar en España, otros aspectos han contribuido a alimentar y sostener la importancia cualitativa y cuantitativa de este sector. Entre ellos, destaca su permeabilidad sector al trabajo informal, algo fundamental teniendo en cuenta que la irregularidad administrativa ha sido una pauta de la inmigración en España, debido a "la estrechez de las vías de acceso regular”, principalmente a partir de 2000, representadas por la contratación en origen a través del contingente de trabajadores extranjeros 4 (Arango, 2005), y hasta 2005, cuando se introduce el catálogo de ocupaciones de difícil cobertura. Así, aunque el contingente incluyera una cuota para empleadas domésticas - algo que a menudo se cita en las investigaciones sobre los regímenes de cuidados en Europa como rasgo carácterístico del caso español-, este mecanismo tenía una escasísima influencia y la principal vía de acceso al empleo de hogar no ha sido nunca la contratación en origen. Al contrario, la principal vía era la contratación de mujeres que vivían en España en situación de irregularidad sobrevenida después de haber accedido al país como turistas. Estas eran contactadas a través de redes informales, tanto personales como mediadas por organizaciones caritativas y sociales, principalmente religiosas.

Al mismo tiempo, para poder presentar una demanda de regularización y poder renovar los permisos temporales de residencia y trabajo, se podía utilizar un contrato privado de empleo de hogar y el alta en el régimen especial de la Seguridad Social para empleados de hogar, algo que reforzaba el interés de este sector como vía de acceso a la regularización administrativa, incluso para quienes no ejercían esa ocupación.

${ }^{3}$ Algunos de los elementos discriminatorios todavía se mantienen en la nueva legislación (Real Decreto 1620/2011) como por ejemplo, la ausencia de prestación por desempleo y de las inspecciones de trabajo. Además, la sindicación sigue siendo extremadamente escasa.

${ }^{4}$ Fue la principal vía de acceso formal al mercado de trabajo español hasta 2005. 
Así, el empleo de hogar ha supuesto una tela de araña en la que se han visto enredadas muchas mujeres migrantes de estos primeros años de inmigración en España: por un lado, ofrecía empleo de fácil acceso para quienes no tenían una situación administrativa regular y utilidad práctica para conseguir regularizarse; por otro lado, el "efecto llamada" provocado por la demanda de fuerza de trabajo en los sectores que la población autóctona estaba rechazando debido al aumento de su "nivel de aceptabilidad" (Cachón, 2009) se concentraba, para las mujeres, en este sector, lo que dejaba ver una demanda especifica de trabajo doméstico mercantilizado debido al escaso reparto de las tareas domésticas entre los géneros y las administraciones públicas. La potencia de las redes informales para conseguir empleo en el sector terminaba de orientar el encuentro entre oferta y demanda. Así, tanto las redes constituidas por las propias comunidades de migrantes como a través de la red de la iglesia católica, que tradicionalmente ha hecho de intermediaria entre las "chicas" del campo y las "señoras" de la ciudad para colocarlas como “domesticas”. Finalmente, una serie de estereotipos étnicos y de género que esencializan a las "mujeres latinas" y su supuesto "cariño con los abuelos" (Pla, 2004: 333) han terminado de crear la etiqueta perfecta para que estas mujeres encajaran perfectamente como la pieza del puzle que el régimen de cuidados español necesitaba para enfrentar el reto del envejecimiento de la población.

En cuanto a las mujeres que participaron en esta investigación, las trayectorias previas a la emigración eran altamente diversas. Con respecto a la formación y la ocupación que tenían en sus países de origen, se ha encontrado una enorme diversidad: una ingeniera civil, una licenciada en Administraciones Públicas y una licenciada en Agronomía que emigraron nada más terminar sus estudios, una psicóloga, una conserje en un colegio, una enfermera, una monja, una secretaria de dirección o una propietaria de un taller de carpintería, entre otros perfiles. Pertenecientes a distintos estratos socioeconómicos y con trayectorias muy diversas, algunas que no habían terminado sus estudios primarios y otras que habían finalizado con éxito una carrera universitaria, es difícil encontrar un patrón común en sus trayectorias. Al contrario, el rasgo que las une es el paso por una ruptura de la trayectoria laboral, y el estatus social previo a la migración y la homogeneización y asimilación a una categoría social única de “mujer inmigrante”, de forma que su única cualificación se convierte, precisamente, en "ser mujer” y "ser latina” (Moré, 2015).

\subsection{El sector formal de atención a las personas mayores}

En este contexto de modelo de cuidados donde prevalece la domesticidad, la Ley de Promoción de la Autonomía Personal y Atención a las personas en situación de dependencia (39/2006) ha sido el primer paso de España hacia una política pública de cuidados. Esta ley establece, por primera vez, en el país un sistema de grados de dependencia para asegurar la protección como un derecho universal, independiente de la edad y de la condición laboral de la persona. Esta ley ha expandido los servicios sociales que existían dando prioridad a los casos de mayor dependencia, establecida en tres grados (grado I, dependencia moderada; grado II, dependencia severa; grado III, gran dependencia) que se miden a través del Baremo para la Valoración de las Situaciones de Necesidad (BSN), que privilegia los criterios médicos y físicos por encima de los sociales. Además, una de las aportaciones fundamentales de la Ley de Dependencia de 2006 han sido las "ayudas" monetarias para cuidadoras no profesionales del ámbito familiar. Sin embargo, estas ayudas están destinadas a familiares y no permiten la contratación de una empleada de hogar, algo que dentro del contexto europeo supone una excepción y que resulta paradójico teniendo en cuenta que la empleada de hogar es la solución que más se utiliza en el contexto español.

Dicho en otras palabras, desde un modelo profesional y medicalizado de los cuidados de larga duración, como es el que propone esta legislación, se puede reforzar el modelo doméstico y desestimar la perspectiva social. La consecuencia es una versión más de lo que ha ocurrido con el reparto por sexos del trabajo doméstico en su conjunto: en vez de implicar a los varones en las tareas del hogar, ha diversificado las categorías del trabajo de las mujeres, estableciendo escalas de importancia y remuneración entre ellas. Las prestaciones económicas que concede la ley son un medio de que una mujer pague a otra mujer en la que delega las tareas de su rol femenino (Fernández, Artiaga y Dávila, 2013: 66).

En Madrid, los servicios sociales para personas mayores dependen del Gobierno municipal y se organizan en torno a la Dirección General de Mayores y Atención Social. De entre los diferentes servicios 5 prestados por esta administración, la mayor partida presupuestaria se dirige hacia el servicio de ayuda a domicilio (SAD). Este servicio tiene su origen en los años ochenta, pero hasta 2003 no ha sido una prioridad en los servicios sociales locales. Aun así, es un servicio muy escaso que alcanza a 52.191 personas usuarias en 2013 para la demanda real que existe en una sociedad tan envejecida, pues supone una cobertura del $8,25 \%$ de las población mayor de 65 años. Desde el punto de vista de su utilidad, éste es un servicio que, si bien puede resolver rápido situaciones de cierta emergencia, en general es poco ágil y requiere permanecer en una lista de espera.

${ }^{5}$ Esta administración presta diferentes servicios siguiendo dos líneas principales de actuación: por un lado, la permanencia de la persona mayor en su entorno habitual, principalmente a través de la implementación de centros de día, servicios de teleasistencia y de ayuda a domicilio; y por otro lado, el envejecimiento activo, fomentado a través de una agenda de actividades diversas pensada para personas autónomas. 
Esto se debe, en gran parte, a que de manera tácita se confía en que la demanda se pueda aplacar con el empleo de hogar, pues el SAD municipal tiene una capacidad relativa de incidencia, debido al escaso número de horas (15,77 horas de media mensual, por persona usuaria), en comparación con el empleo de hogar.

Desde que se aprobó la Ley de Dependencia, este servicio se ha ido orientando hacia personas muy dependientes, según criterios médicos, o que se encuentran en situación de gran riesgo social. Las administraciones locales lo financian y realizan las evaluaciones de dependencia a los potenciales usuarios pero quienes lo prestan son empresas privadas. En comparación a los servicios de ayuda a domicilio en París, el SAD madrileño está muy controlado por la administración municipal y hay escaso margen de elección a las personas usuarias, por ejemplo, la empresa que va a prestar los servicios viene determinada por el lugar de residencia. Existe la posibilidad de cofinanciación entre las administraciones públicas y los usuarios, pero desde el inicio de la crisis el servicio está en declive, debido a la falta de financiación. Así, en 2009 se atendieron 54.400 personas (2.209 menos que en 2009) y en el periodo $2009-2013$ se ha reducido en $856.220^{6}$ el número total de horas de servicio prestadas. En el año 2013 si bien el presupuesto se mantiene con respecto al año anterior, sólo se ha ejecutado un $78 \%$, lo que da lugar a una cifra ficticia de gasto. Además, se ha rebajado el precio por hora de servicio que el ayuntamiento paga a las empresas prestatarias como medida para ahorrar dinero pero sin reducir el volumen de personas atendidas. Por tanto, las trabajadoras se encuentran con un perfil de personas usuarias cada vez más dependientes pero con un valor asignado a la intervención cada vez más bajo. En lo que respecta a la definición de los puestos de trabajo se reconoce una única categoría genérica de trabajadoras (auxiliar a domicilio) que puede realizar cualquier tipo de intervención o tarea y hasta 2015 no se ha requerido ninguna formación específica ni titulación oficial a las trabajadoras.

En cuanto a las residencias, que es donde principalmente ha aplicado el modelo profesional del cuidado, es bastante difícil analizar el sector en su conjunto, debido a la gran diversidad de tipos de centros: en función de su tamaño y de la titularidad, que puede ser privada o pública, con o sin ánimo de lucro, pero además porque la gestión puede estar contratada a empresas privadas, y finalmente en un mismo centro suele haber plazas tanto privadas como concertadas. Sin embargo, se advierten tendencias comunes al sector, las cuales son similares a las ya señaladas para la ayuda a domicilio: por un lado, la concentración de centros y la evolución hacia un modelo más comercial que

${ }^{6}$ Según las memorias de actividades publicadas por la Dirección General del Mayor y de Atención Social del Ayuntamiento de Madrid, el SAD Municipal prestó en 2009 un total de 8.106.591,40 horas, y en $2013,7.250 .371,50$. social; por otro, la tendencia hacia la medicalización de los servicios que se ofrecen y, en consecuencia, el cambio del perfil de las personas mayores desde la necesidad económica y social hacia la dependencia.

Durante la década de 2000, ha habido una época de gran crecimiento del sector que se ha visto frenado desde el comienzo de la crisis económica, en parte porque estaba bastante asociado al sector de la construcción y a la especulación inmobiliaria. Tradicionalmente se trataba de un sector formado a partir de pequeñas empresas que a raíz del bum inmobiliario, de la creciente necesidad social ante el envejecimiento de la población y de las nuevas posibilidades que ofrecía el marco de la Ley de Dependencia, se había convertido en un sector de negocio para las empresas constructoras. La tendencia en el sector es hacia la concentración, aunque todavía hay muchas empresas pequeñas y medianas pero a las que les cuesta adaptarse a los estándares de demanda de servicios. Este modelo orientado hacia una visión profesional de los cuidados - con personal titulado, como terapeutas ocupacionales y fisioterapeutas, con módulos especializados en alzhéimer o barreras arquitectónicas- basada en la dependencia como criterio de acceso, conlleva unos costes por plaza más elevados y ha convertido las residencias en un negocio altamente rentable pero que no siempre tiene como consecuencia una mejor atención.

\subsection{De empleadas domésticas a cuidadoras profesionales}

En cuanto a la fuerza de trabajo que sostiene este sector formal de los CLD se trata también de manera mayoritaria de mujeres de origen inmigrante. Muchas de ellas tienen experiencia en cuidados al haber trabajado como empleadas de hogar durante un periodo previo a la regularización de su permiso de residencia en España. Durante el periodo de expansión del sector, que coincide con la década de 2000, al no exigirse ninguna titulación oficial y haber una fuerte demanda de trabajo, la experiencia en cuidados informales a domicilio y la garantía de haber hecho "algún" curso era suficiente para introducirse en el sector formal, como explica una trabajadora rememorando su paso del empleo doméstico a una residencia:

Entonces, en alta voz, la chica [en una bolsa de empleo de servicio doméstico] dijo: “Urgente, ¡urgente! ¡Necesito alguien que tenga un certificado de cuidar personas mayores! Alguien que haya hecho un cursillo, un curso, algo". Y había jtantas chicas!, pero yo dije: “¡Yo!” Así fue. Y me dijeron: "Vas a ir a una residencia". Y dije: “Bueno”. Y me dijeron: “¿Tu tarjeta?”. “Mi tarjeta es de doméstica”. Pero la residencia me hizo un trámite y me mandó desde el inicio al régimen general [de la Seguridad Social]. [...] Y bueno, voy a la residencia. Me mandan a no sé dónde por Pozuelo y me hacen el contrato por seis 
meses ya de entrada. Desde la primera tarde, no me preguntan si sabes o si no sabes, desde la primera tarde: uniforme, zapatos y a la primera planta. (Estela, 50 años, Ecuador, en Madrid desde 1999, ha sido empleada de hogar “interna”, externa, auxiliar a domicilio y en residencia; tiene doble nacionalidad.)

Estos años de expansión dieron lugar a la etnización del sector, que en pocos años pasó a estar compuesto mayoritariamente por trabajadoras extranjeras, principalmente procedentes de Ecuador y de otros países sudamericanos. Esta fase se caracteriza por dos fenómenos sociales de adaptación. En primer lugar, la ruptura de las resistencias de la población autóctona, y concretamente de las personas mayores, que son las potenciales usuarias de estos servicios. Así explica este proceso una coordinadora del SAD:

Al principio sí nos pedían españolas, pero luego ya se dieron cuenta de que... o sea, yo en mi plantilla tengo 35 personas y españolas tengo tres. Entonces, a mí me pedían una española y yo les decía: "Es que las españolas no van a trabajar, o sea, no van a solicitar este trabajo". [...] Son sobre todo latinoamericanas, de Ecuador y Perú sobre todo. (Coordinadora de empresa prestadora del SAD, Madrid, 2012)

En este sentido, Parella (2004) señalaba que las empresas más institucionalizadas en el sector en la región metropolitana de Barcelona, entre las que se encuentran aquellas que prestan los servicios del SAD, pretendían ofrecer por encima de todo una imagen de profesionalidad y calidad. Sin embargo, los usuarios acostumbraban a solicitarles mujeres autóctonas, a pesar de que los mecanismos de asignación de los puestos de trabajo y de retribución que estas empresas intentaban mantener seguían pautas formalizadas, basándose principalmente en la cualificación profesional, y no tanto en el componente étnico como indicador indirecto de características de naturaleza personal, como la sumisión o la docilidad (Parella, 2004: 193). Como vemos, una década después de la investigación llevada a cabo por Parella y en la región metropolitana madrileña, las mujeres latinoamericanas han conseguido emprender un proceso de profesionalización, gracias en muchos casos a una cualificación informal y autodidacta, entrando desde los puestos de trabajo más duros del sector de atención doméstica - los empleos de interna- hasta llegar a ocupar mayoritariamente los puestos más estables -entendiendo este calificativo de manera relativa- del sector de los cuidados a domicilio. Desde la perspectiva de los procesos migratorios de las trabajadoras, encontramos una experiencia generacional compartida de pérdida de estatus social y de la cualificación profesional anterior a su instalación en España, para luego emprender un camino de profesionalización de la experiencia adquirida por defecto en el ámbito de los cuidados geriátricos. Los flujos migratorios de mujeres latinoamericanas hacia España han sido tan fuertes y concentrados que podemos hablar de una experiencia migratoria generacional pues los perfiles, las trayectorias y las historias, aunque con sus particularidades, tienen muchas características en común.

En la trayectoria laboral de muchas de las trabajadoras de los cuidados, este paso del sector informal al formal supone un cambio importante hacia una profesionalización, aunque sea precaria, y una nueva etapa en la carrera migratoria (Martiniello y Rea, 2014) que se caracteriza por una mayor estabilidad administrativa. El trabajo en las residencias o en el SAD forma parte de una trayectoria laboral ascendente que comienza con la descualificación y el desclasamiento que sufrieron en el contexto de inserción laboral en España. Además, comenzar a trabajar en una empresa de ayuda a domicilio o en la plantilla de una residencia supone, para las empleadas de hogar, una mejora en sus condiciones laborales y un mayor reconocimiento, como explica esta trabajadora:

A mí me conviene, por donde se mire, trabajar en residencias. [...] Cuando estás trabajando con personas en una casa, tú no puedes salir, porque tienes que cuidar al abuelo, que es como un bebé. [...] En las casas, no hay los beneficios que puedes tener en las empresas, por ejemplo, si por hache o por be quieres parar de trabajar, puedes hacerlo, porque tienes el paro. También te pagan si has trabajado los festivos. Por el contrario, puedo decir que, con los abuelos así, en casa, yo no he recibido nunca nada. (Francisca, 50 años, Ecuador, en Madrid desde 1999; ha sido empleada de hogar "interna" y auxiliar en residencia; posee un título de formación profesional en Auxiliar de Enfermería; tiene doble nacionalidad)

La mejora en la trayectoria laboral con respecto al empleo de hogar es relativa, pues en ocasiones los salarios son más bajos, pero a cambio se alejan de situaciones de servidumbre doméstica y se accede a la economía formal.

El sector se ha caracterizado por la intensa circulación de las trabajadoras de unos empleos a otros, pues hay una gran proporción de contratos definidos y de corta duración, generalmente de menos de un año. Así, una misma persona acumula breves experiencias de trabajo en distintos centros, como residencias o centros de día, pero también a domicilio, tanto formal como informal, por tanto, manejan gran cantidad de información sobre el sector y sobre cómo moverse en él. A pesar de que no siempre dispongan de títulos oficiales, estas trabajadoras han adquirido a través de la experiencia laboral y la formación en contextos informales, y a un conocimiento y unas competencias dirigidas al cuidado específico de las personas mayores (Avril, 2006: 95).

Debido a los bajos salarios en los cuidados formales, generalmente por debajo de los 900 euros por jornada completa, se suelen combinar varios trabajos 
y el empleo de hogar supone a menudo una manera de complementar el salario "haciendo unas horas". Por tanto, no se produce una ruptura total con el sector menos formal. Además, al no existir una promoción dentro de la categoría genérica de auxiliar a domicilio o auxiliar de geriatría, la proyección hacia otros puestos de trabajo más cualificados es muy escasa. Así, el salto hacia otras categorías, como la de auxiliar de enfermería, es difícil y aun cuando se realiza la formación profesional el acceso al trabajo en hospitales u otros centros con un público más heterogéneo, resulta extremadamente difícil para quienes se han especializado en los cuidados de larga duración a personas mayores.

De manera paralela a la profesionalización de algunas empleadas de hogar, el sector del servicio doméstico ha ido absorbiendo nueva mano de obra, femenina y migrante, recién llegada a España. Por tanto, la composición étnica y nacional del sector se ha ido transformando de la mano de la imposición de visados a determinadas nacionalidades, de la estabilización y regularización de la población inmigrante asentada en España y por el establecimiento de nuevos flujos migratorios (Oso, 1998; Escrivá, 2000; Colectivo loé, 2001, Marcu, 2009), pero la pauta de la etnicización e irregularidad se ha mantenido (Rodríguez et al., 2012: 185).

\subsection{La crisis como freno a las trayectorias ascendentes}

El contexto de crisis supone un nuevo punto de inflexión en la evolución de las trayectorias laborales dentro del sector de los cuidados de larga duración. Por un lado, el empleo de hogar ya no crece como lo hacía antes de la crisis, y pese a no ser uno de los más castigados por el desempleo, sí se ha reducido la circulación de ofertas de trabajo. Además, las condiciones laborales han empeorado de manera dramática y han bajado los salarios como consecuencia de un aumento de la competencia por los escasos empleos, que atraen incluso a sectores de población que antes los rechazaban sistemáticamente (hombres inmigrantes y mujeres españolas). Sin embargo, los empleos para cuidar mayores, en régimen interno, siguen demandándose, pues responden a necesidades urgentes y no a gasto suntuario. Por ello, para aumentar las posibilidades de conseguir trabajo a las candidatas, las religiosas de una conocida bolsa de empleo doméstico en Madrid han optado por poner en la ficha que la preferencia es "de interna”, aunque esta no sea la opción que las demandantes de empleo desean.

Por otro lado, en las empresas del SAD y las residencias cada vez se exige una mayor formación y experiencia a las candidatas. Si antes de la crisis no era necesario ningún título, ahora es difícil trabajar si un diploma de auxiliar de enfermería. Además, el Servicio Nacional de Dependencia ha impulsado un proceso de profesionalización en 2008 , haciendo obligatoria la obtención de títulos oficiales en
2015, aunque debido a la falta de financiación, este proceso ha tenido dificultades para implementarse. Este cierre profesional coincide con un momento de contención del gasto y la inversión empresarial, que está haciendo que se reduzcan los puestos de trabajo en el sector. Por tanto, ante la escasez de empleos y la presión del aumento de la oferta de trabajo, muchas de las personas que habían emprendido una trayectoria de profesionalización vuelven a refugiarse en el empleo de hogar, en lugar de evolucionar de manera ascendente:

[...] y ya estuve en el paro, me puse al paro, que llevaba años trabajando. Me metí de interna porque mi marido se quedó sin trabajo, y la situación económica nuestra no iba bien [...] Entonces yo necesitaba cobrar el paro y trabajar en negro, porque tenía que yo llevar toda la casa, todo, las niñas y todo. (Rudy, 43 años, Ecuador; en Italia 1997-2000, en Madrid desde 2000; nacionalidad española; empleada de hogar interna y externa, auxiliar a domicilio y en residencia; posee un título de formación profesional en Auxiliar de Enfermería)

Como muestra el ejemplo anterior, a consecuencia de la falta de oportunidades de trabajo formal algunas empleadas “profesionalizadas” están volviendo a emplearse como internas (Moré, 2013). Otras, en cambio consideran su asentamiento en España como una fase transitoria su carrera migratoria hacia otros países de Europa. Así, la ciudadanía española y la profesionalización en los cuidados geriátricos son dos objetivos concretos para poder después instalarse en otro país de la Unión Europea (ibídem.).

\section{Configuración del cuidado en París: un modelo social en vías de "industrialización"}

\subsection{Empleo de hogar subvencionado}

En Francia, si bien en la actualidad el empleo de hogar de contratación directa tiene una importancia menor que en España, el servicio doméstico ha tenido un papel importante considerando una perspectiva histórica. A comienzos del siglo XX, constituía el $5 \%$ del empleo total y era frecuente en las familias burguesas, para ir luego disminuyendo a partir de la segunda mitad del siglo, hasta que, a partir de finales de los ochenta, se vuelve a producir un aumento, principalmente a través del empleo directo de personal a domicilio (Devetter, JanyCatrice, Ribault, 2010: 19).

El inesperado crecimiento de los empleos a domicilio, y especialmente entre particulares, es una pauta común en los dos países. Sin embargo, el papel desempeñado por las instituciones públicas en cada caso es totalmente diferente. En Francia, las políticas públicas han promovido el aumento de este sector, a través de su regulación, respondiendo a un 
doble objetivo: por un lado, producir un estímulo al empleo, tanto creando nuevos puestos de trabajo, como reduciendo el empleo informal; y por otro, atajar las necesidades de cuidados surgidas de las transformaciones en las dinámicas familiares y la incorporación de las mujeres al mercado laboral.

El objetivo político de creación de empleo a través de los servicios de proximidad se orienta, en primer lugar, hacia la reducción de impuestos, lo que va a producir un crecimiento de las actividades, del empleo en los servicios familiares y del número de horas trabajadas. En este sentido, las políticas públicas permitieron una deducción fiscal anual media de cerca de 12.000 euros por hogar y la creación de unos 700.000 empleos directos en el periodo 1990-2006 (Balzani, 2010: 13).

A partir de finales de los ochenta, el Estado comienza a exonerar de las cargas sociales a los empleadores para fomentar los empleos de ayuda familiar y hacer emerger de la informalidad el empleo no declarado. Desde 1987, se exonera de las cargas patronales a los empleadores particulares discapacitados o mayores de 70 años, una medida que favorece la creación del público de las personas mayores como potenciales empleadores directos de servicios a domicilio (Dussuet, 2005: 49), algo que hasta entonces se hacía por medio de asociaciones sin ánimo de lucro. Así, a partir de 1987 las estructuras tradicionales de ayuda a domicilio se van a ver forzadas a abrir su actividad hacia los servicios llamados preceptivos, en los que si bien no son empleadoras, se ocupan de gestionar la relación salarial. A las exoneraciones fiscales se suma una serie de mecanismos que van a facilitar las gestiones para la contratación de una empleada a domicilio. Además de los ya señalados servicios preceptivos, se introduce el pago del salario a través de cheques; desde 1994, los cheques-servicio (CES); y desde 2005, los cheques-servicio universal (CESU) CESU, que son el medio utilizado por los dos tercios de los trabajadores del sector (Merckling, 2011: 99).

A pesar de estas condiciones de incentivación del empleo de hogar "directo", el recurso a contratar a una empleada cuidadora por un número sustancial de horas sigue siendo un servicio de relativo lujo y poco frecuente (Merckling, 2011: 100). En la actualidad, el empleo directo en el hogar en Francia se asocia principalmente con la realización de tareas domésticas y de limpieza para particulares válidos, especialmente parejas de clase media, que optan por recurrir a una femme de menage para aliviar las tensiones conyugales respecto al trabajo doméstico (Molinier, 2009: 114).

\subsection{Informalidad y cuidados en el hogar}

La puesta en práctica de un sistema de ayudas públicas y deducciones fiscales destinadas a satisfacer las necesidades de cuidados ha contribuido enormemente a la disminución del empleo informal no declarado en Francia. Según Marbot (2008, cit. en
Hirata, 2011), el peso del empleo informal ha pasado de representar el $50 \%$ al $30 \%$ de los empleos a domicilio en el periodo 1995-2005. A pesar de ello, el empleo no declarado continua siendo una realidad para una proporción significativa de empleadas a domicilio en Francia (Devetter, Jany-Catrice, Ribault, 2010: 50), principalmente para las de origen migrante (Hirata, 2011: 200). Si bien la formalización de la relación laboral otorga una visibilidad jurídica al empleo de hogar, la mejora de las condiciones de trabajo de las empleadas de hogar es escasa, debido a que la formalización beneficia ante todo a los empleadores, quienes pueden solicitar una subvención, y no a las trabajadoras, quienes no tienen por qué ver modificadas sus condiciones laborales ni el reconocimiento de las tareas que realizan (Devetter y Rousseau: 2011: 30).

Si bien no es una práctica mayoritaria, en esta investigación se ha identificado un sector de la alta burguesía parisina, tradicionalmente empleadores de servicio doméstico, que han ido transformando la demanda en empleos de cuidados según “las señoras" iban envejeciendo. Esta demanda especifica se organiza a través redes católicas que llevan décadas orientando a las mujeres extranjeras hispanohablantes hacia empleos domésticos en los barrios acomodados de la ciudad (Oso, 2004). Al igual que encontraba Liliane Mozère en su investigación sobre las empleadas filipinas en París, a menudo las cuidadoras que se han encontrado en esta investigación se encontraban en situación irregular y sus empleadores no tenían interés en las ventajas fiscales que les podría ocasionar la formalización de la relación laboral (Mozère, 2002: 374). La vía de acceso al país que más se repetía era la entrada como turista, permaneciendo después diez años de manera irregular hasta conseguir el permiso de residencia excepcional, como es el caso de Luna, una mujer de 50 años, colombiana, que lleva en Francia desde 1994 y siempre ha trabajado como empleada de hogar cuidando mayores:

Al principio, no tenía papeles, tuve que esperar diez años. Porque por ley me pertenecían a los diez años si cumplía los requisitos: un contrato de arrendamiento, constancia de que uno ha estado yendo al médico, facturas de cosas que ha comprado, que ha pagado, muchas cosas. (Luna, 50 años, Colombia; en París desde 1994; empleada de hogar interna y externa cuidando mayores, permiso de residencia y trabajo)

Entre 1994 y 2004, vivió en París en situación de irregularidad administrativa, pero a ella nunca le faltó trabajo como empleada en casas particulares. Cuando consiguió regularizar su situación y accedió a un permiso de residencia y trabajo, continuó, sin embargo, trabajando en empleo del hogar, cuidando de personas mayores más o menos de la misma forma que lo había hecho hasta entonces. Esta inmovilidad laboral se debe tanto a una barrera formal, ya que su escasa competencia escrita del francés dificulta su acceso a los servicios de ayuda 
a domicilio (donde suele hacerse un examen escrito en la entrevista laboral) y a la falta de un incentivo para dejar el empleo de hogar, ya que cuenta con un trabajo estable cuidando de una anciana, con plenos derechos a prestaciones sociales y bien remunerado.

\subsection{El modelo social de ayuda a domicilio}

Estos servicios de ayuda a domicilio para personas mayores o fragilizadas tienen una larga tradición histórica ligada a asociaciones sin ánimo de lucro y con fines filantrópicos o caritativos, de inspiración laica o religiosa, que se crearon como redes de solidaridad local para hacer frente a los desastres provocados por la Segunda Guerra Mundial. Los servicios de ayuda a domicilio han permanecido, hasta finales de los años noventa, fuera de la lógica mercantil, pues estaban inscritos en una lógica social, bajo una regulación tutelar del Estado y fuera de la esfera doméstica (Devetter, Jany-Catrice, Ribault, 2010: 28). En cuanto a su financiación, durante todo el siglo XX y hasta $1995^{7}$, la ayuda a las personas mayores dependientes a domicilio provenía de los mecanismos de ayuda vinculados a situaciones de pobreza y fragilidad social, se organizaban a escala local y reposaban en gran medida sobre el trabajo doméstico gratuito y de proximidad (Weber, 2014: 32).

Este sistema de ayuda a domicilio basado en la tradición social y sin ánimo de lucro se ha sostenido gracias a un importante sector asociativo, que sigue siendo el principal proveedor de servicios de ayuda a domicilio en Francia (Lada, 2011: 10). Los poderes públicos han considerado que este sector asociativo no sólo era una respuesta al problema del envejecimiento de la población y a la atención a la dependencia, sino que también podía ser una solución eficaz para hacer frente al desempleo estructural. Por ello, se han emprendido numerosas reformas destinadas a estimular la demanda, siguiendo la misma lógica de "libre elección” que en el empleo directo.

Lada (2011) caracteriza una primera etapa de reformas en el sector asociativo de la ayuda a domicilio - desde los años noventa hasta 2005en la que las medidas, apoyadas por sindicatos y asociaciones, se dirigían principalmente hacia la formación y la cualificación de las trabajadoras y, por tanto, hacia la dignificación de las condiciones laborales y la calidad del servicio. En este sentido, se estableció el proceso de reconocimiento de la experiencia como parte de la formación profesional

7 Los dos mecanismos principales eran una ayuda financiera; la ayuda compensatoria para una tercera persona (ACTP), con la que los consejos generales financiaban a las personas discapacitadas pobres independientemente de su edad; y una ayuda domestica a las personas mayores pobres, servicio prestado por organismos como LOS centros de acción social, asociaciones locales o ayuntamientos. En 1995, se introduce por primera vez una prestación experimental de dependencia (PED); en 1997, la prestación especifica de dependencia (PSD); y en 2002, la prestación de pérdida de autonomía (APA).
(VAE), la creación del diploma oficial DEAVS (que sustituye al CAFAD, que sólo estaba abierto a las personas que ya estaban empleadas en el sector) y el acuerdo de sector que en $\mathbf{2 0 0 2}$ ha revalorizado las remuneraciones, ofreciendo nuevas posibilidades en términos de carrera y de reconocimiento de conocimientos y competencias (Lada, 2011: 12). Por otra parte, esto supone una jerarquización de las trabajadoras a través de un cierre profesional. De esta manera, quienes no tienen el diploma oficial no pueden realizar ciertas tareas más cualificadas, como por ejemplo, duchar a la persona mayor, y ven reducidas su actividad a las tareas domésticas y las compras, algo que no sucede en Madrid, donde las trabajadoras son polivalentes.

Sin embargo, una segunda etapa de reformas comienza a partir de 2005 , con la implementación del Plan de Cohesión Social, más conocido como Plan Borloo, que aplica una lógica de mercado para introducir el sector en el segmento competitivo del mercado de trabajo, lo que se ha producido sin que aumentara la demanda y, por tanto, harán más frágiles las nuevas mejoras en las condiciones laborales y de la profesionalización de las trabajadoras (Lada, 2011: 13). Esta política ha llevado a privilegiar una "convención de profesionalidad mercantil" sobre otras lógicas posibles en las que se asentaba la ayuda a domicilio (Ribault, 2008).

Así, se obliga a las asociaciones a competir entre ellas y con las empresas privadas o con los empleadores particulares, al tiempo que aquellas tienden a diversificar su actividad, perdiendo la función social por la que fueron creadas. Además, se ha producido un movimiento de concentración de asociaciones pequeñas, a través de absorciones, así como una diversificación de sus servicios para hacer frente al nuevo contexto. Todo ello tiene consecuencias sobre la organización del trabajo, sus límites, tiempos, la estandarización de tareas, la producción de normas de calidad o la creación de una nueva jerarquía técnica en las asociaciones. Estas herramientas de control y gestión de la fuerza de trabajo son importadas del sector mercantil y obedecen a una serie de normas que son elaboradas a distancia, y que no tienen en cuenta la complejidad y características particulares del sector, por lo que a menudo entran en contradicción con la lógica de la ayuda a domicilio a personas mayores (Lada, 2011: 14). En este mismo sentido, Weber (2014: 39-40) analiza el conjunto de estos cambios como el paso de un modelo social a un modelo industrial ("el sector de la ayuda a domicilio ha atravesado, desde la década de 2000 , un proceso de racionalización industrial de las tareas").

\subsection{La reproducción social como yacimiento de empleo}

Desde década de $\mathbf{2 0 0 0}$, se ha considerado este sector como un "yacimiento de empleo", pero para un sector de la población muy específico -mujeres 
mayores, con escasa formación y principalmente inmigrantes o descendientes de la inmigración-, que se considera "difícilmente empleable" en el mercado laboral. Efectivamente, el sector de la ayuda a domicilio en la región metropolitana parisina está compuesto, en gran medida, por mujeres migrantes o descendientes de la inmigración (muchas de ellas, de África subsahariana y el Magreb) y originarias de los territorios franceses de ultramar, como las islas de Martinica o Guadalupe, por lo que los estereotipos y discriminaciones raciales están fuertemente presentes (Avril, 2014: 23).

Puesto que el fenómeno de la inmigración en Francia tiene una larga trayectoria ${ }^{8}$, mucho más antigua, diversa y compleja en que en España, la composición migratoria de una metrópolis como París presenta mucha diversidad en términos sociodemográficos (lugares de origen, época de llegada a Francia, edad actual y edad cuando migraron), de la cual el sector de la ayuda a domicilio es un fiel reflejo. En un estudio sobre las trayectorias laborales de las auxiliares a domicilio, se observaba una diferencia relevante entre aquellas migrantes "indiferenciables" y aquellas que "parecen extranjeras", ya sea debido al nombre 0 al fenotipo: mientras que las primeras tienen unas experiencias parecidas a las francesas no migrantes, las segundas se encontraban en lo más bajo de las escalas de cualificación y tenían trayectorias más marcadas por la inestabilidad (Doniol-Shaw, Lada, Dussuet, 2007: 267-270).

En el contexto de la región de París, el sector de los cuidados está etnicizado, más que formado por personas inmigrantes, pues se trata de trabajadoras que encajan con unas características que hacen que se las considere extranjeras, no sólo por motivos jurídicos (nacionalidad extranjera), sino también raciales, pues como explica esta coordinadora, el hecho de no ser "cien por cien blanca" remite a un posible origen extranjero:

Tenemos una gran mayoría que son de origen extranjero, eh, incluso si han nacido en Francia..., pero no son cien por cien blancas, no. Sí, hay una gran parte (extranjera) una gran parte. (Coordinadora de asociación de ayuda a domicilio, París, 2013)

Un ejemplo de la política de orientar a las mujeres inmigrantes hacia este sector es el protocolo de acuerdo firmado en junio de 2008 entre los servicios de empleo, la Agencia Nacional de Servicios a la Persona (ANSP) y la Dirección de Acogida, de Integración y de Ciudadanía (DAIC), que depende del Ministerio de Inmigración. Este acuerdo fijaba distintos dispositivos para sensibilizar y orientar a las mujeres inmigrantes hacia "las potencialidades

${ }^{8}$ En 1893 , tiene lugar la primera legislación que regula la inmigración en Francia y que traza, por primera vez, el vínculo entre la intervención del Estado sobre el mercado de trabajo y la definición de los extranjeros. Se trata de la Ley relativa a la Residencia de los Extranjeros en Francia y a la Protección del Trabajo Nacional. En cambio, en España la primera ley relativa a la inmigración data de 1986. de empleo ofrecidas por el sector de servicios a la persona". Al contrario de lo que ocurría en Madrid, donde el papel del Estado en la relación inmigración y empleos de cuidados consiste fundamentalmente en mantenerse ausente, en este caso son las instituciones del Estado, a través de los servicios de empleo, quienes contribuyen a orientar la fuerza de trabajo femenina y racializada hacia la creciente demanda de trabajo de cuidados.

\subsection{Una prestación universal para la pérdida de autonomía}

Con la prestación experimental de dependencia (PED, 1995), la prestación especifica de dependencia (PSD, 1997) y la prestación personalizada de autonomía (APA, 2002), en Francia la dependencia se separa del paradigma de la ayuda social para configurarse como una categoría universal de la acción pública, definida por la ley y que abre el derecho a prestaciones en especie (servicios a domicilio o en instituciones) financiados por el Estado y los consejos generales. Ese cambio de paradigma significa que no se trata de ayudar a las personas sin recursos cuando están en situación de dependencia o de discapacidad, sino de dotar de un derecho universal a todas las personas mayores dependientes (Weber, 2014: 13).

Con respecto a las ayudas anteriores, la APA ha disparado la prestación de servicios a domicilio $-y$ no en instituciones-, puesto que no sólo es universal -aunque la cantidad final dependa también de los ingresos-, sino que además se diferencia de las prestaciones anteriores (PED y PSD) en que, cuando se utiliza para prestación de servicios a domicilio, no es recuperable después de la sucesión y no obliga a la manutención, como sí ocurría con la PED y la PSD. Sin embargo, los costes de alojamiento (hébergement) de personas mayores dependientes en una institución (Ehpad) siguen estando a su cargo y al de sus familiares. Esta particularidad de la APA ha supuesto un crecimiento exponencial de los servicios de ayuda a domicilio, multiplicándose por seis las cantidades de gasto de ayuda a domicilio (de 38 millones de euros a 250 millones de euros) y aumentado el número de trabajadores declarados (un $80 \%$ más en el periodo 2003-2008) [Billaud, Trabut y Weber, 2014: 42]. Los criterios de elegibilidad de la APA son dos: el nivel de dependencia según criterios medicalizados -la escala Aggir y los grados GIR-; y el nivel de ingresos del hogar, cuando se trata de cuidados a domicilio.

Sin embargo, el modelo de cuidados centrado en la APA y la ayuda a domicilio se enfrenta a dificultades en su financiación. Por un lado, en un contexto de envejecimiento demográfico cada vez hay más demandantes de esta ayuda, puesto que se trata de un derecho universal para mayores de 65 años. Por otro, las administraciones locales (los consejos generales) que se encargan de su financiación tienen que recurrir a incrementar los impuestos locales para afrontar el aumento de estas partidas en sus 
presupuestos. Ante esta situación, a menudo la inversión en la cualificación de las trabajadoras se perfila como variable de ajuste para reducir el coste de estas prestaciones (Lada, 2011). Una solución interesante, y que ha mantenido el vínculo con el modelo social francés de solidaridad nacional, familiar y profesional, ha sido la instauración de un día de trabajo suplementario cuyos beneficios son transferidos de las empresas a la Caja Nacional de Solidaridad por la Autonomía (CNSA) para contribuir a la financiación de la APA (Weber, 2014: 33).

\subsection{La construcción de una jerarquía profesional}

En cuanto a las trayectorias de las trabajadoras, existe una clara división entre las empleadas de hogar que se dedican a los cuidados y las trabajadoras del sector formal. Para estas últimas, al contrario que en Madrid, en los servicios de ayuda a domicilio en Francia existe una clasificación jerarquizada en función de sus niveles de competencia: las trabajadoras de nivel A sólo son aptas para realizar tareas de limpieza; las de nivel $B$ pueden realizar tareas de limpieza y compras; las de nivel C pueden hacer limpieza, compras, aseos y acompañamientos. Para acceder a los niveles $B$ y $C$ es necesario cursar una formación específica. El nivel C corresponde a un título oficial, el diploma de Estado de Auxiliar de Vida Social (DEAVS). Evidentemente, esto supone una serie de barreras en las trayectorias de las trabajadoras, especialmente para aquellas que no manejan bien el idioma francés, pues las pruebas escritas son obligatorias. Para quienes acceden desde el nivel $A$, esto supone una trayectoria de cierta movilidad ascendente, pero quienes acceden directamente desde el nivel $C$ se encuentran estancadas, sin poder promocionar a puestos de mayor responsabilidad. En todo caso, el discurso de la profesionalidad ha calado en estos servicios, algo que no sucede en Madrid.

En cuanto al trabajo en residencias, de nuevo al contrario de lo que suceden en Madrid, para acceder a un empleo de auxiliar en una residencia en París es necesario tener un título oficial, generalmente de auxiliar de enfermería, aunque también en algunos casos puede ser válido el DEAVS. Al igual que ocurre con las auxiliares a domicilio, esta categoría de profesional está muy feminizada y racializada. El sector ofrece estabilidad a las trabajadoras, pues los contratos fijos son frecuentes y, en muchos casos, se establecen desde el principio de su relación laboral. Sin embargo, hay mucha circulación en el sector pues las auxiliares de enfermería prefieren trabajar en hospitales y consideran las residencias como lugares "de paso" o "para el fin de carrera". Muchas de las auxiliares entrevistadas mostraban su determinación de continuar estudiando para ser enfermeras, algo que pueden hacer sin tener que realizar el bachillerato o estudios superiores, debido a que existen "pasarelas" de formación para las auxiliares de enfermería. Entre las migrantes, todas querían asentarse definitivamente en Francia, al menos hasta la edad de jubilación, algo que presenta una gran diferencia con el caso de Madrid, donde la re-migración era una posibilidad que muchas trabajadoras consideraban.

\section{Conclusiones}

Las intersecciones entre los regímenes de cuidados y migratorios dan lugar a marcos institucionales locales que son el contexto específico en el que se realizan los trabajos de cuidados. Los regímenes de cuidados no son, sin embargo, homogéneos y coherentes, sino que concentran una gran diversidad de tradiciones locales, actores sociales e institucionales, y de mecanismos políticos que pueden derivar de lógicas diversas en función del desarrollo histórico de cada contexto específico. En cada una de las dos ciudades estudiadas, se articulan modelos de cuidados que remiten a tres lógicas distintas: doméstica, social y profesional, lo que da lugar a configuraciones sociales del cuidado específicas, pero también dinámicas y en constante renegociación.

En Madrid, predominan los cuidados domésticos prestados por empleadas de hogar, muchas veces en régimen interno, siguiendo un modelo lo más parecido posible a los cuidados gratuitos y "por amor" prestados en las relaciones familiares. Este modelo de cuidados domésticos pero mercantilizados se caracteriza por requerir de las empleadas una enorme flexibilidad y disponibilidad, tanto en tiempos de trabajo como en implicación personal con las personas mayores. Los cuidados han salido del ámbito familiar, pero trasladando una organización doméstica hacia el mercado y exigiendo de las trabajadoras unas demandas propias del ámbito no mercantil. Esta mercantilización de la domesticidad se ha sostenido sobre la fuerza de trabajo, extremadamente precarizada, de las mujeres migrantes llegadas a España desde mediados de los años noventa. Una política migratoria que fomentaba la irregularidad administrativa ha contribuido a mantener este sistema, creando una bolsa de trabajadoras en situación irregular que estaban dispuestas a aceptar los peores empleos del mercado laboral. A su vez, estos cuidados domésticos conviven con un modelo de servicios sociales, basado en la lógica de atención social integral a las personas mayores como colectivo que requiere especial protección. En este sentido, los servicios sociales dirigidos a personas mayores en Madrid forman una red relativamente reciente y que sólo cubre las necesidades de los más desprotegidos. Este modelo, tanto a domicilio como en residencias, está siendo amenazado por los recortes presupuestarios ligados a la crisis económica.

En París, el modelo social de cuidados de larga duración ha predominado desde la segunda mitad del siglo XX, a través de una amplia red de servicios de ayuda a domicilio cuyos principales proveedores son asociaciones sin ánimo de lucro. 
La lógica profesional se ha combinado con este modelo social para dar lugar a una clasificación profesional ligada a titulaciones oficiales, que han contribuido relativamente a revalorizar esos empleos y a reducir la precariedad de las trabajadoras. Además, siguiendo una lógica economicista que enfatiza la rentabilidad de estos servicios, se están incorporando elementos de gestión y de racionalización del trabajo diseñados sin considerar las personas a las que se dirigen. De manera paralela a estos procesos, ha habido una re-domesticación de los cuidados, a través de la subvención pública, vía desgravación fiscal, para quienes empleen de manera directa servicios en el hogar. El objetivo de este estímulo a la demanda ha sido incentivar el empleo de personas que tienen un acceso difícil al mercado laboral, como las mujeres de mediana edad, sin estudios, las mujeres migrantes o las descendientes de la inmigración. Los acuerdos firmados en 2008 entre la Oficina Francesa de la Inmigración y de la Integración (OFII) y la Agencia Nacional de Servicios a la Persona (ANSP) muestran cómo los poderes públicos también participan en la etnización del sector de los cuidados, en concreto, al orientar los servicios de empleo hacia esos puestos del mercado laboral.

La comparación de estos dos casos muestra cómo el problema de la limitación de la interacción entre los regímenes de cuidados y migratorio confina a las mujeres migrantes a los empleos de cuidados, como sucede claramente en Madrid; pero también revela que no se trata sólo de un problema coyuntural al que se enfrenta una generación de migrantes, que tras un desclasamiento en la migración pueden recuperar su posición, sino que, como sucede en París, las mujeres racializadas ocupan una posición estructural en los mercados de trabajo asociada a los peores puestos, los menos valorados, que coinciden con los del sector de los cuidados. Si bien en Madrid se observa que las trayectorias ascendentes son difíciles, incluso sin salir del sector de los cuidados, en París se constata que la etnicización del sector de los cuidados va más allá de una cuestión migratoria y de ciudadanía, sino que tiene directamente implicaciones raciales. 
ARANGO, J. (2005): La inmigración en España: impactos demográficos, económicos y sociales, Avilés, Escuela de Verano UGT.

AVRIL, C. (2014): Les aides à domicile. Un autre monde populaire, París, La Dispute.

- (2006): Le travail des aides à domicile pour les personnes âgées: contraintes et savoir-faire", Le Mouvement Social, $\mathrm{n}$-216, págs. 87-99.

BALZANI, B. (2010): Les services à la personne, París, La Documentation Française.

BILLAUD, S.; TRABUT, L.; y WEBER, F. (2014): L'échec du modèle industriel, en WEBER, F.; TRABUT, L.; y BILLAUD, S. (dirs.), Le Salaire de la confiance: l'aide à domicile aujourd'hui, París, Éditions Rue d’Ulm, págs. 41-46.

CACHÓN, L. (2009): La España inmigrante: marco discriminatorio, mercado de trabajo y políticas de integración, Barcelona, Anthropos.

CARRASCO, C. (2013): "El cuidado como eje vertebrador de una nueva economía", Cuadernos de Relaciones Laborales, vol. 31, nํㅜ 1, págs. 39-56.

CARRASCO, C.; y MAYORDOMO, M. (1999): Tiempos, trabajos y organización social: reflexiones en torno al mercado laboral femenino, en CARRASCO, C. (ed.), Mujeres y economía. Nuevas perspectivas para viejos y nuevos problemas, Barcelona, Icaria, págs. 125-171.

COLECTIVO IOÉ (2001): Mujer, trabajo e inmigración, Madrid, Instituto de Migraciones y Servicios Sociales.

- (1990): El servicio doméstico en España. Entre el trabajo invisible y la economía sumergida, Madrid, Juventud Obrera Cristiana de España.

COLECTIVO IOÉ; y FERNÁNDEZ, M. (2010): Encuesta Nacional de Inmigrantes 2007: el mercado de trabajo y las redes sociales de los inmigrantes, serie Documentos del Observatorio Permanente de la Inmigración, ํㅜ 24, Madrid, Ministerio de Trabajo e Inmigración.

CUZZOCREA, A.; y LYON, D. (2011): "Sociological conceptualisations of 'career': A review and reorientation", Sociology Compass, vol. 5 , nํㅜ 12, págs. 1.029-1.043.

DEVETTER, F. X.; y ROUSSEAU, S. (2011): Du balai. Essai sur le ménage à domicile et le retour de la domesticité, París, Raisons d'Agir.

DEVETTER, F. X.; ANY-CATRICE, F.; y RIBAULT, T. (2010): Les services à la personne, París, La Découverte.

DONIOL-SHAW, G.; LADA, E.; y DUSSUET, A. (2007): Les parcours professionnels des femmes dans les métiers de l'aide à la personne. Leviers et freins à la qualification et à la promotion, París, Université Paris-Est.

DUSSUET, A. (2005): Travaux de femmes. Enquêtes sur les services à domicile, París, L'Harmattan.

ESCRIVÁ, Á. (2000): “¿Empleadas de por vida? Peruanas en el servicio doméstico de Barcelona", Papers, nํ6, págs. 327-342.

ESPAÑA (2011): “Real Decreto 1620/2011, de 14 de noviembre, por el que se regula la relación laboral de carácter especial del servicio del hogar familiar", Boletín Oficial del Estado, nํ 277, 17-11-11, págs. 119.046119.057 [rhttp://www.boe.es/buscar/doc. php?id=BOE-A-2011-17975'].

- (2006): “Ley 39/2006, de 14 de diciembre, de Promoción de la Autonomía Personal y Atención a las Personas en Situación de Dependencia", Boletín Oficial del Estado, no 299, 15-12-06, págs. 44.142-44.156 [<http://www.boe.es/ buscar/doc.php?id=BOE-A-2006-21990>]. 
- (1985): "Real Decreto 1424/1985, de 1 de agosto, por el que se regula la relación laboral de carácter especial del Servicio del Hogar Familiar", Boletín Oficial del Estado, no-193, 13-8-85, págs. 25.617-25.618 [rhttp://www.boe.es/buscar/ doc.php?id=BOE-A-1985-17108>].

EVETTS, J. (2007): “Analysing change in women's careers: Culture, structure and action dimensions", Gender, Work and Organization, vol. 7, nㅜ 1, págs. 57-67.

FERNÁNDEZ, C.; ARTIAGA, A.; y DÁVILA, C. (2013): “Cuidados, género y transformación de identidades", Cuadernos de Relaciones Laborales, vol. 31, no 1 , págs. 57-89.

FISCHER, B.; y TRONTO, J. (1990): Towards A Feminist Theory of Care, en ABEL, E. K.; y NELSON, M. K. (dirs.), Circles of Care, Albany, State University of New York Press.

GUIMARÃES, N. A.; HIRATA, H.; y SUGITA, K. (2011): “Cuidado e cuidadoras: o trabalho de care no Brasil, França e Japão", Sociologia e Antropologia, vol. 1, n-1, págs. 151- 180.

HIRATA, H. (2011): "Questions sur la qualité des emplois du care: France, Brésil, Japon", Travail, Genre et Sociétés, vol. 2, nํ26, págs. 199-203.

KERGOAT, D. (2000): Division sexuelle du travail et rapports sociaux de sexe, en HIRATA, H. et al. (coords.), Dictionnaire critique du féminisme, París, PUF, págs. 34-44.

KING, R.; y ZONTINI, E. (2000): "The role of gender in the South European immigration model”, Papers, n 60 , págs. 35-52.

LADA, E. (2011): “Les recompositions du travail d'aide à domicile en France", Formation et Emploi, no 115 , págs. 9-22.

LYON, D.; y GLUCKSMANN, M. (2008): “Comparative configurations of care work across Europe", Sociology, vol. 42, $\mathrm{n}^{\circ}$ 1, págs. 101-118.

MARCU, S. (2009): “Inmigrantes rumanas en el servicio doméstico y de cuidados de la Comunidad de Madrid", Estudios Geográficos, $\mathrm{n}^{\circ} 70$, págs. 463-489.

MARTÍN-PALOMO, M. T. (2008): “'Domesticar’ el trabajo: una reflexión a partir de los cuidados", Cuadernos de Relaciones Laborales, vol. 26, $\mathrm{n}$ 을, págs. 13-44.

MARTÍNEZ-BUJÁN, R. (2014): “¡El trabajo doméstico cuenta! Características y transformaciones del servicio doméstico en España", Migraciones, nํㅜ 36, págs. 275-305.

- (2011): "La reorganización de los cuidados familiares en un contexto de migración internacional”, Cuadernos de Relaciones Laborales, vol. 29, no 1, págs. 93-123.

MARTINIELLO, M.; y REA, A. (2014): "The concept of migratory careers: Elements for a new theoretical perspective of contemporary human mobility", Current Sociology, vol. 62, no 7 , págs. 1079-1096

MERCKLING, O. (2011): Femmes de l'immigration dans le travail précaire, París, L’Harmattan.

MOLINIER, P. (2009): “Des féministes et de leurs femmes de ménage: entre réciprocité du care et souhait de dépersonnalisation", Multitudes, $\mathrm{n}$ - 37-38, págs. 113-121.
- (2006): Le care à l'épreuve du travail. Vulnérabilités croisées et savoir-faire discrets", en PAPERMAN, P.; y LAUGIER, S., Le souci des autres. Éthique et politique du care, París, Editions de l'EHESS, págs. 299-316.

MORÉ, P. (2015): When Your CV is 'To Be a Latina Woman': The Rearticulation of Stereotypes Affecting the Identity of Ecuadorian Women in the Care and Domestic Sector, en LA BARBERA M. C. (ed.) Identity and Migration in Europe: Multidisciplinary Perspectives, Cham, Springer, págs. 193-208.

- (2013): “La vuelta de las 'internas’: crisis y condiciones laborales en el empleo de hogar y el trabajo de cuidados", Sociología del Trabajo, $n^{\circ} 79$, págs. 30-48.

MOZÈRE, L. (2002): “Des domestiques philippines à París, un marché mondial de la domesticité?", Revue Tiers Monde, vol. 43, ํㅜㅜ 170, págs. 373-396.

OSO, L. (2004): Españolas en París. Estrategias de ahorro y consumo en las migraciones internacionales, Barcelona, Ediciones Bellaterra.

- (1998): La migración hacia España de mujeres jefas de hogar, Madrid, Instituto de la Mujer.

PAJARES, M. (2009): Inmigración y mercado de trabajo. Informe 2009, Madrid, Ministerio de Trabajo e Inmigración.

PARELLA, S. (2004): Mujer, inmigrante y trabajadora: la triple discriminación, Barcelona, Anthropos.

PÉREZ-OROZCO, A. (2014): Subversión feminista de la economía. Aportes para un debate sobre el conflicto capital-vida, Madrid, Traficantes de Sueños.

PLA, I. et al. (2004): Informalidad del empleo y precariedad laboral de las empleadas de hogar, Valencia, Instituto de la Mujer de la Generalitat Valenciana; Valencia, Universidad de Valencia.

RIBAULT, T. (2008): “Aide à domicile: de l'idéologie de la professionnalisation à la pluralité des professionnalités", Revue Française de SocioÉconomie, vol. 2, no 2, págs. 99-118.

RODRÍGUEZ, V. (ed.) (2012): Inmigración y cuidados de mayores en la Comunidad de Madrid, Madrid, BBVA.

SALLÉ, M. A. (1985): Situación del servicio doméstico en España, Madrid, Instituto de la Mujer.

SARASÚA, C. (1994): Criados, nodrizas y amos. El servicio doméstico en la formación del mercado madrileño, Madrid, Siglo XXI.

SHUTES, I.; y WALSH, K. (2012): “Negotiating user preferences, discrimination, and demand for migrant labour in long-term care”, Social Politics, vol. 19, $\mathrm{n} \mathrm{N}^{0}$ 1, págs. 78-104.

TORNS, T. (1995): “Mercado laboral y desigualdades de género", Cuadernos de Relaciones Laborales, no 6, págs. 81-92.

VIDAL-COSO, E.; y MIRET, P. (2009): “Labour trajectories of immigrant women in Spain: Towards a social upward mobility?", Papers de Demografia, no 353 , págs. 1-31.

WEBER, F. (2014): "Le maintien à domicile: à quel prix?", en WEBER, F.; TRABUT, L.; y BILLAUD, S. (dir.), Le Salaire de la confiance. L'aide à domicile aujourd'hui, París, Éditions Rue d'Ulm, págs. 9-40. 